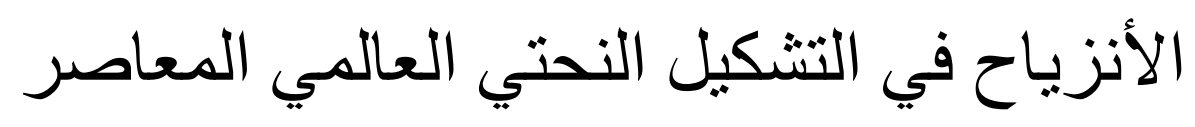

\title{
Displacement in Contemporary Sculptural Formation
}

\author{
Ahmed Khlaif Mankhi
}

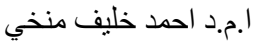

جامعة ميسان /كلية التربية الاساسية/ قسم التربية الفنية

DOI: $10.37648 /$ ijrssh.v10i04.039

Received:18 ${ }^{\text {th }}$ November, 2020; Accepted:12 ${ }^{\text {th }}$ December, 2020; Published: 18th December, 2020

\section{ABSTRACT}

Displacement is one of the concepts that have a great role in understanding artistic texts, as the text opened and made it continue in an active and dynamic way with the participation of the recipient, who became part of the creative process. He dealt with the concept of displacement through what specialists said by setting a definition for it and the mechanisms of its operation. As for the second topic, it dealt with the functions of displacement in contemporary sculptural formation by making the artistic effect as an open text that accommodates all the opinions and perceptions that the recipient drops on the text. Then the research procedures that dealt with two models, the first representing Europe The second is America for the year 2020, and the researcher has reached a set of results, then the research sources come.

يعد الانزياح واحدا من البحث المفاهيم التي لهادور كبير في فهم النصوص الفنية فقد فتح النص وجعله يستمر بشكل فاعل ودينامي بمشاركة المتلقي الذي اصبح جزء من العملية

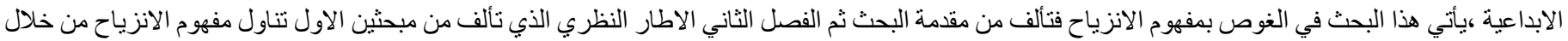

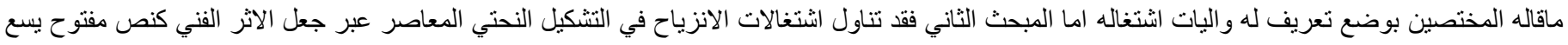

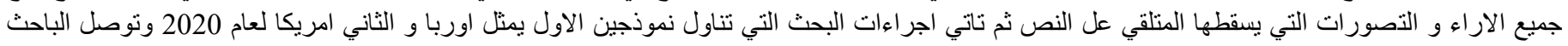
مجمو عة نتائج ثم ناتي مصادر البحث.

الفصل الاول: المقدمة

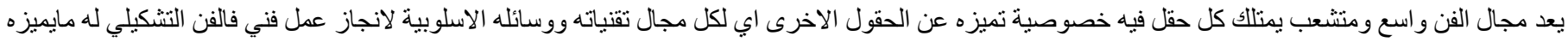

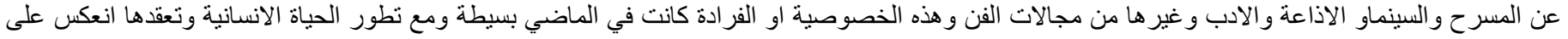

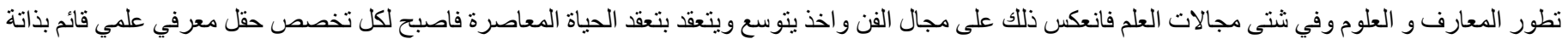

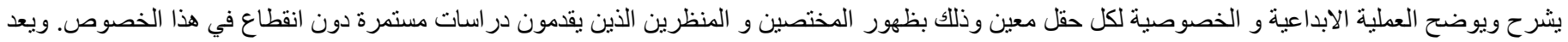

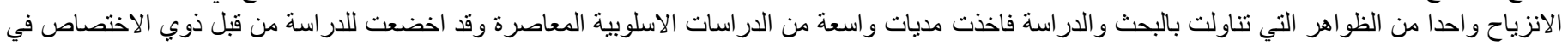

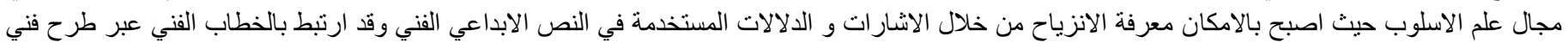

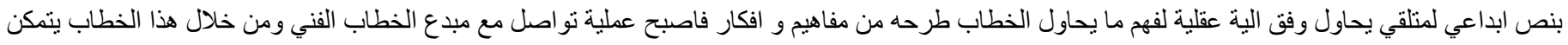
المنلقي الخوض في الانزي اعنياح.

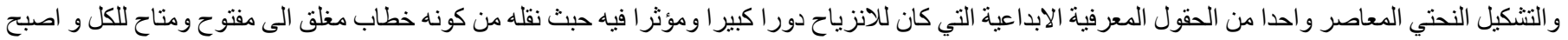

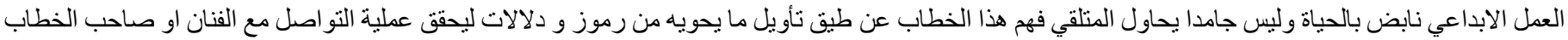

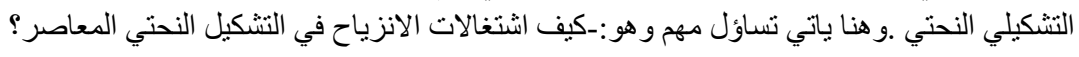


International Journal of Research in Social Sciences and Humanities

(IJRSSH) 2020, Vol. No. 10, Issue No. IV, Oct-Dec

الكلمة المفتاحية (الانزياح،تثكيل ،معاصر)

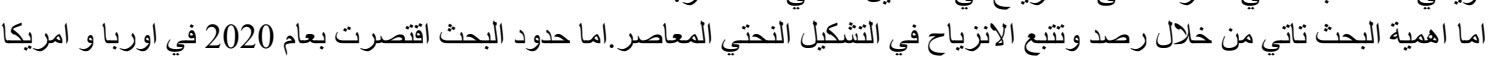

تحديد المصطلحات:

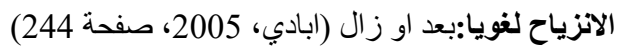

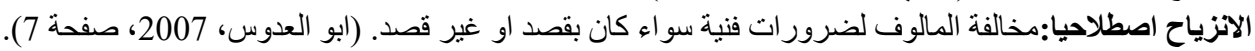

الانزياح اجرائيا:لتحقيق ناثير على المنلقي.

\section{المبحث الاول

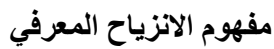

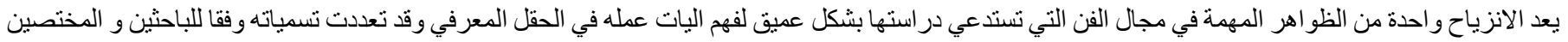

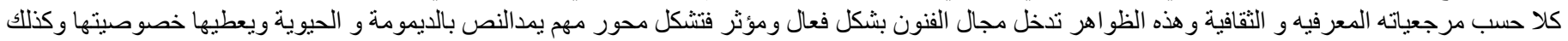

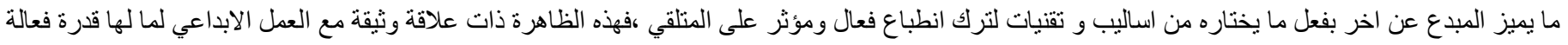

ومؤثره في النص الفني.

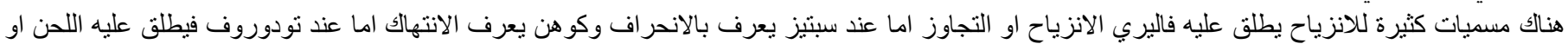

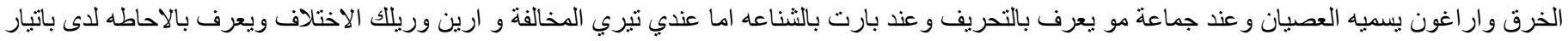

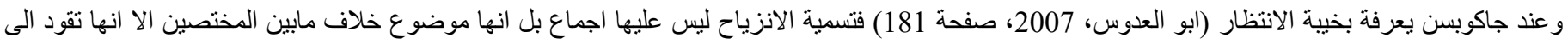

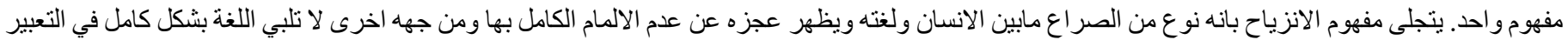

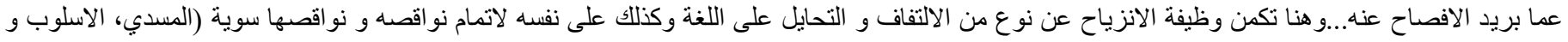

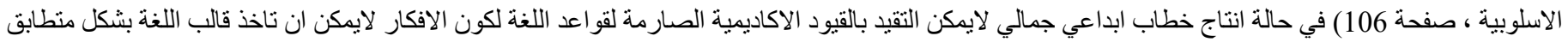

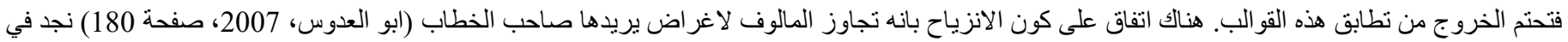

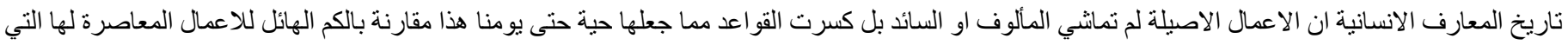

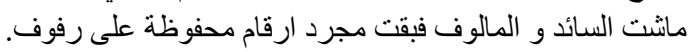

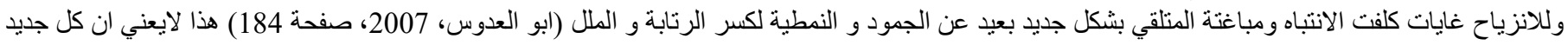

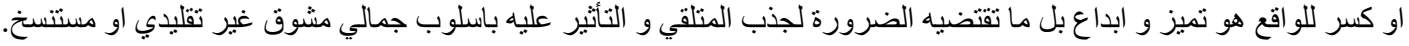

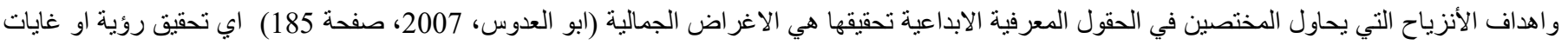
خاصة لها علاقة بالمبدع. يكون الانزياح ابعاد الكلام عن سياقه المعروف و هو فعل لغوب لغوي يكون ضمن صياغة و ونثكيل الكلام ومن خلاله يمكن معرفة الاسلوب الفني وبذللك يعد الاسلوب الفني هو

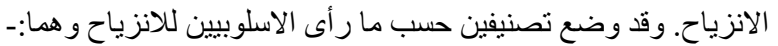

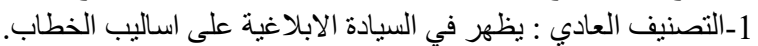

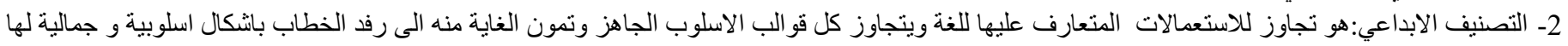

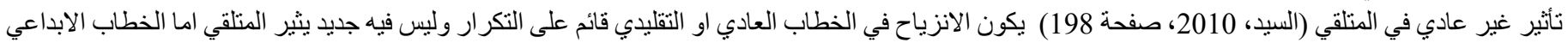
نجه غني بكل ماهو جديد ومثير للمتلقي.

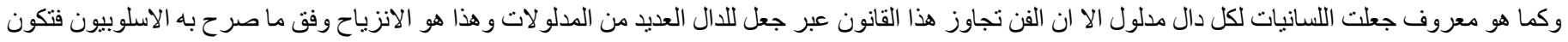

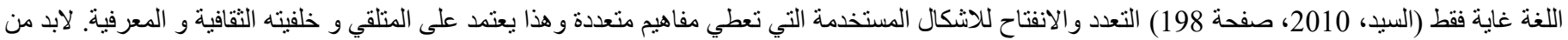

الاشارة الى حقيقتين لها الصلة بالانزياح:-

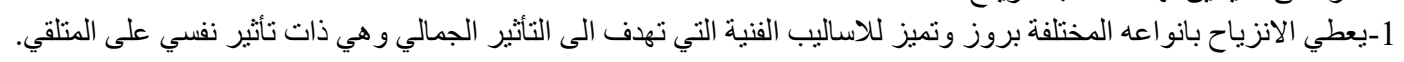

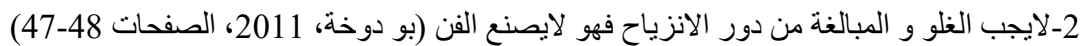

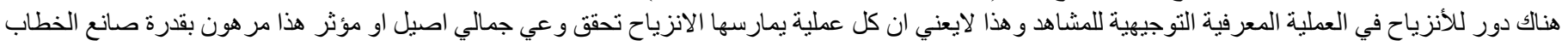

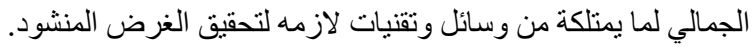

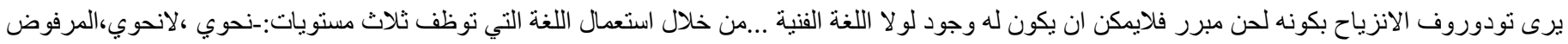

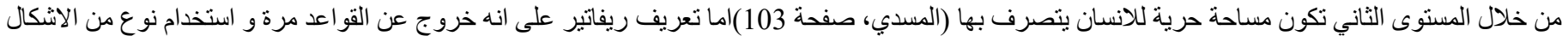

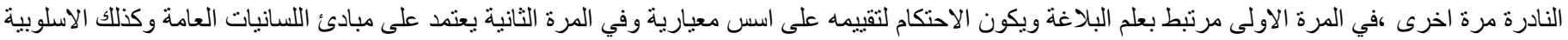

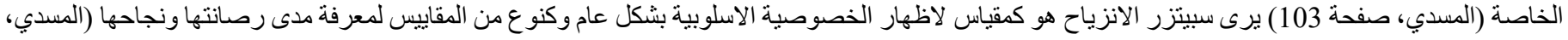

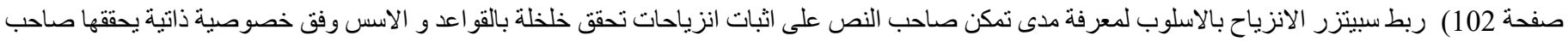
النص التي تميزه عن غيره بين كوهن على ان الانزياح مفهوم صعب بقوله :يعد من المفاهيم المعقدة و المتغيره استحالة توظيفه من دون اي احتياطات (ويس، 2005،

صفحة 103) تصنيز 
International Journal of Research in Social Sciences and Humanities

(IJRSSH) 2020, Vol. No. 10, Issue No. IV, Oct-Dec

وقد وضع الانزياح في خمس نماذج طبقا لتصنيف الغربيين:-

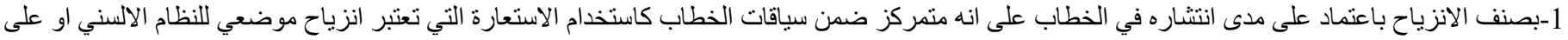

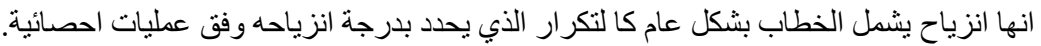

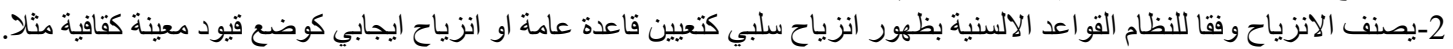

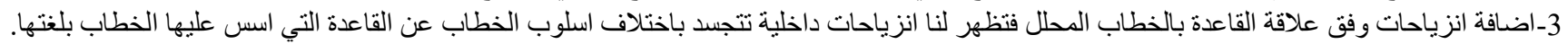

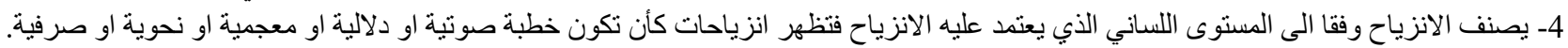

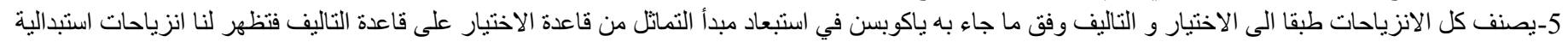

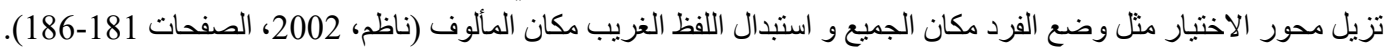

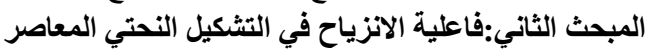

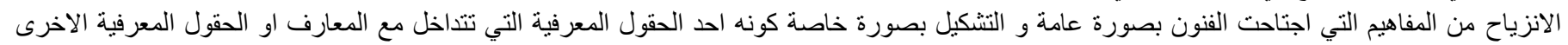

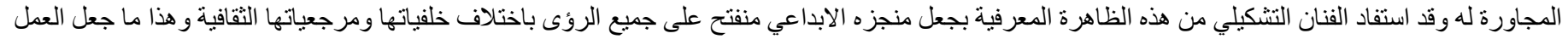

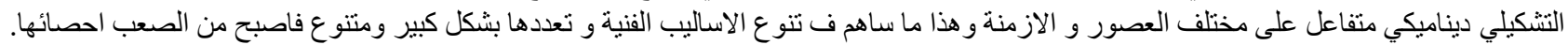

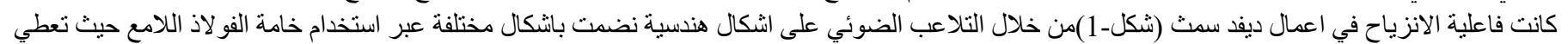

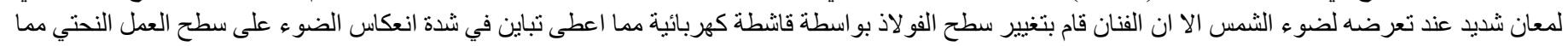

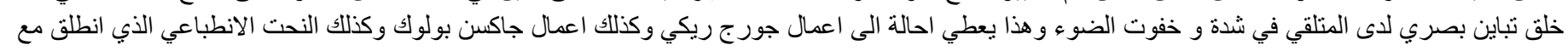

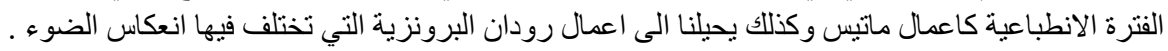

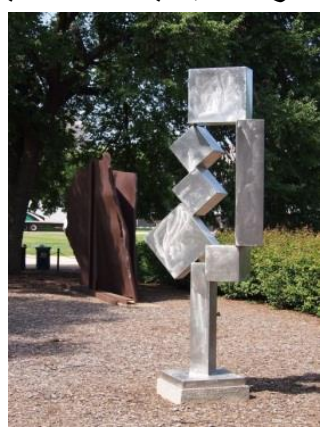

(1) (1) (1) (1)

اما الفنان جورج ريكي الذي اعتمد على خلفيته المهنية لكونه مهندس تقني في معهد ماساتشوستس تجلى ذلك في انجازه الفني وتخصص في النحت الحركي فقدم اعمال

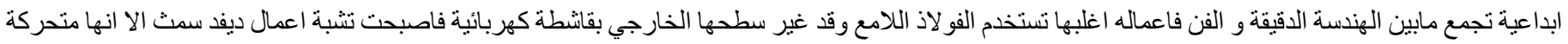

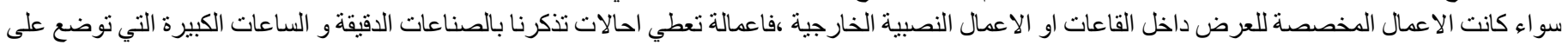

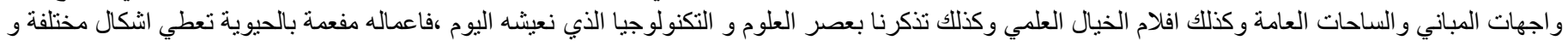

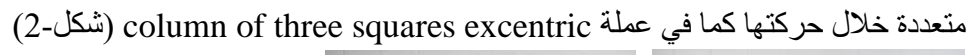
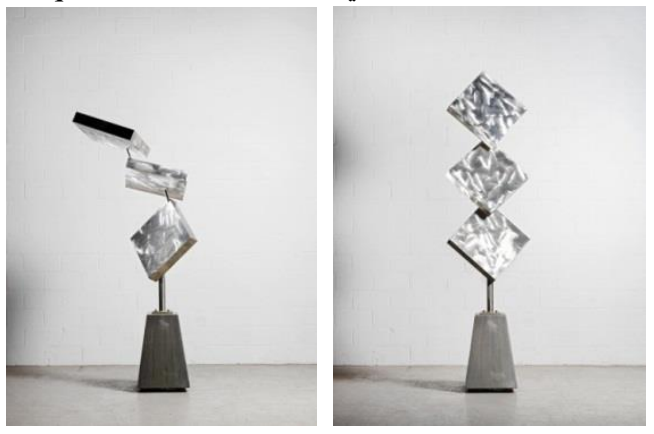

(شكل) (م-2)

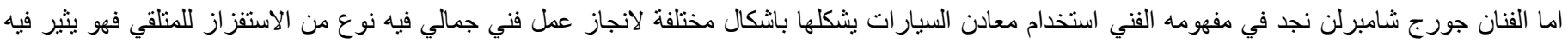

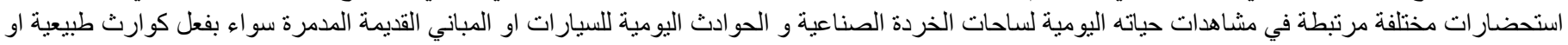

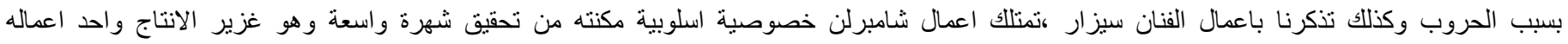

(شكل)gloveboxcollision 
International Journal of Research in Social Sciences and Humanities

(IJRSSH) 2020, Vol. No. 10, Issue No. IV, Oct-Dec http://www.ijrssh.com

e-ISSN: 2249-4642, p-ISSN: 2454-4671

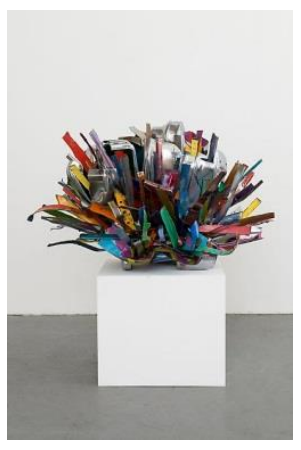

(شكل-3)

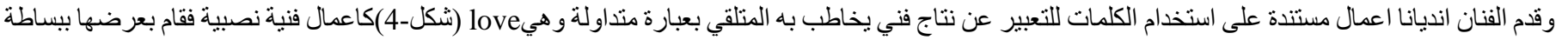

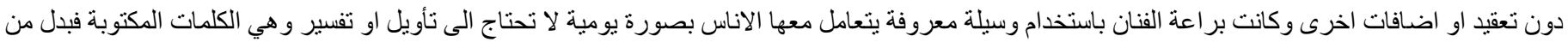

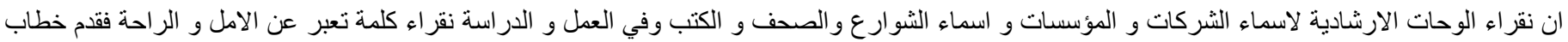

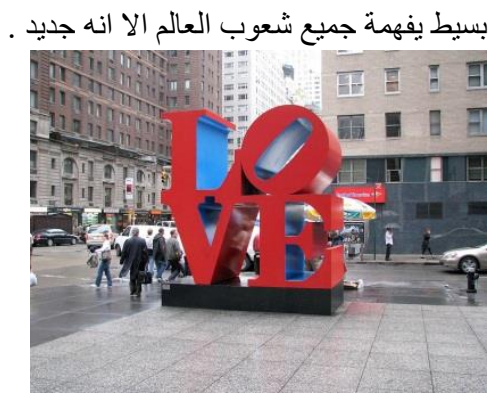

(شكل-4)

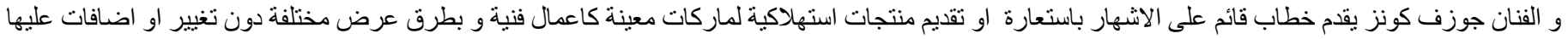

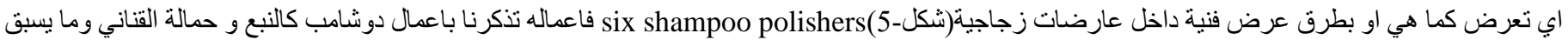

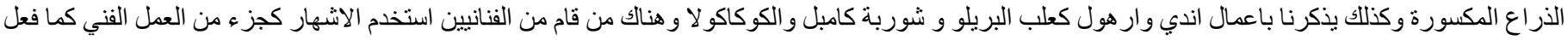

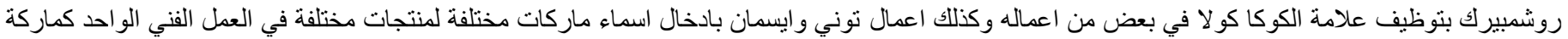
صابون ومسحوق الغسيل و غير ها من الماركات المختلفة في لاعن.

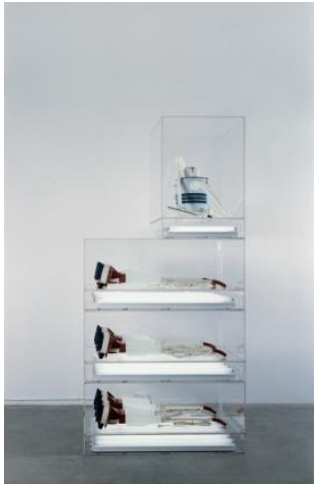

(شكل-5)

ويقدم لنا الفنان الهولندي ثيو يانسن ابداع فني حركي يستخدم انابيب بلاستلك لتنكيل الالات ذات اثكال سريالية متحركة بفعل قوة الريح فهي تجمع مابين بساطة الاشكال

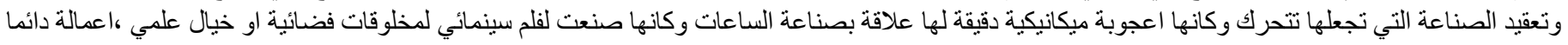

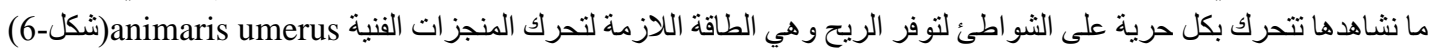


International Journal of Research in Social Sciences and Humanities

(IJRSSH) 2020, Vol. No. 10, Issue No. IV, Oct-Dec

http://www.ijrssh.com

e-ISSN: 2249-4642, p-ISSN: 2454-4671

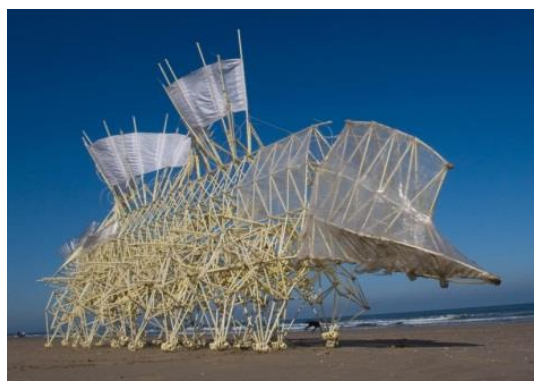

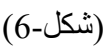

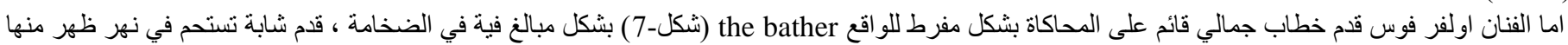

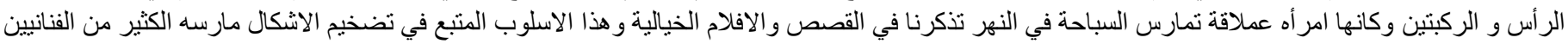

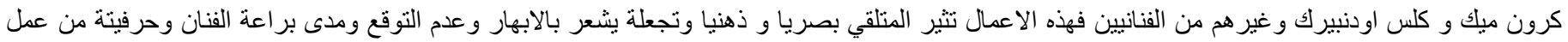

التفاصيل الدقيقة مما يجعل العمل وكانه حقيقي نابض في الحياة.

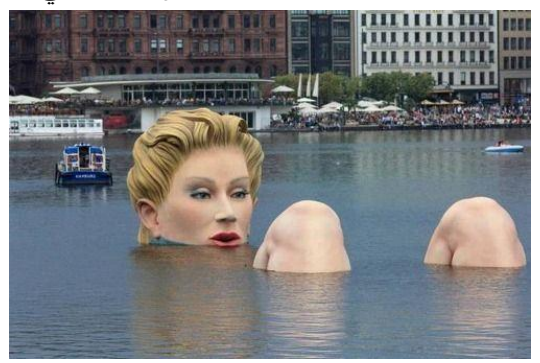

(شكل-7)

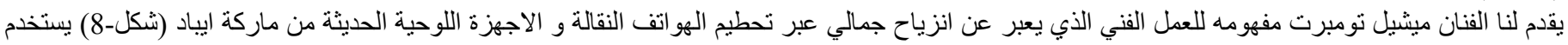

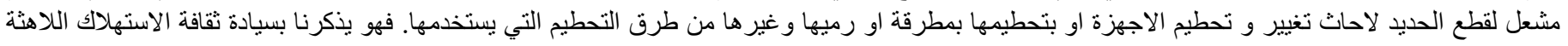

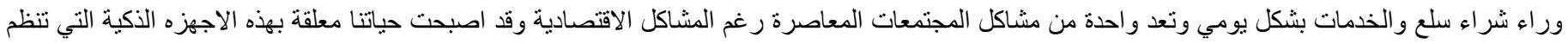

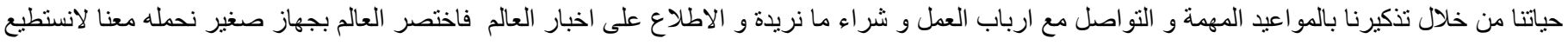

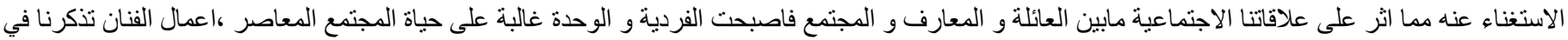

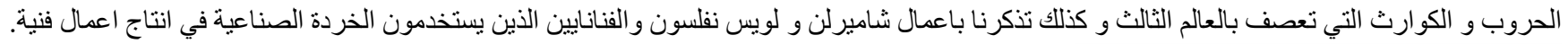

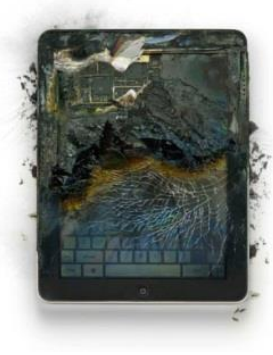

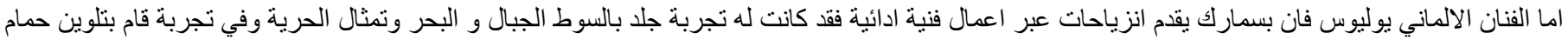

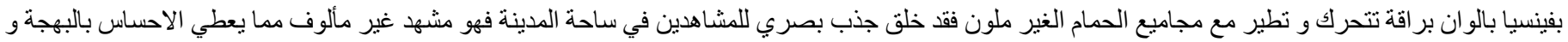

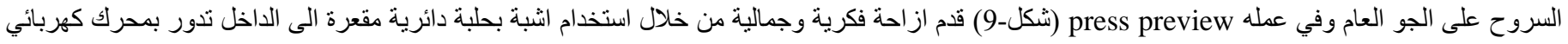

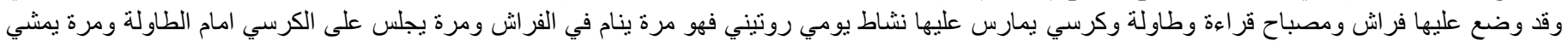

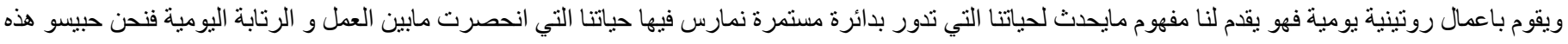

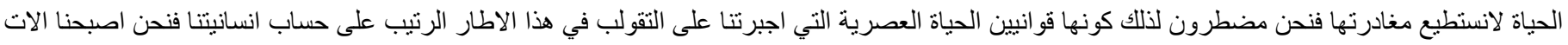
دون مشاعر. 
International Journal of Research in Social Sciences and Humanities

(IJRSSH) 2020, Vol. No. 10, Issue No. IV, Oct-Dec http://www.ijrssh.com

e-ISSN: 2249-4642, p-ISSN: 2454-4671

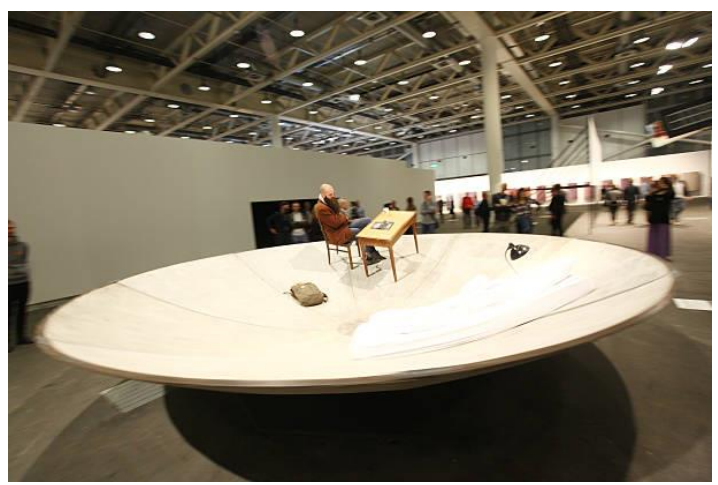

(شكل-9)

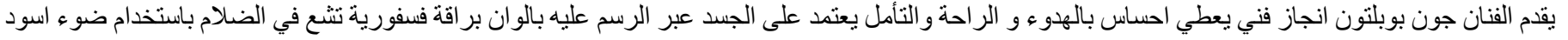

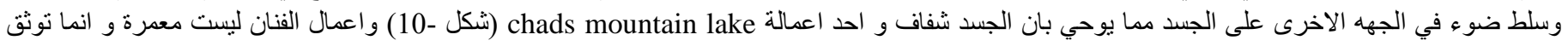
وتعرض بالصور الفوتو غرافية كاعمال فنية هنا الفنان استخدم وسيط بدل العمل الاصلي كعمل فني لاظهاره للجمهور.

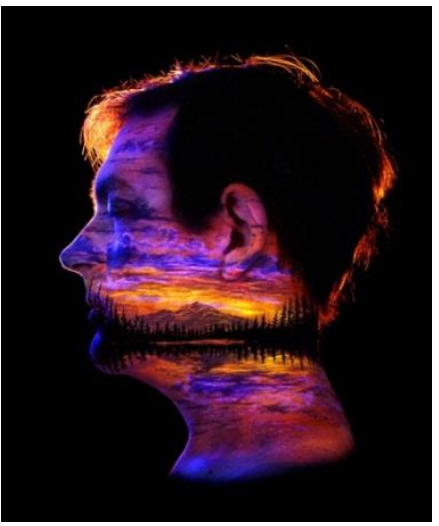

(شكل-10)

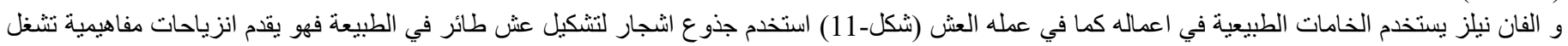

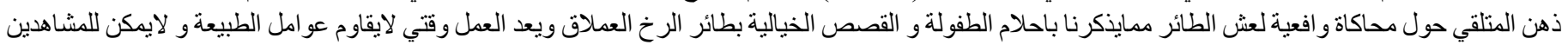

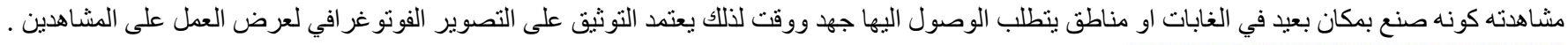

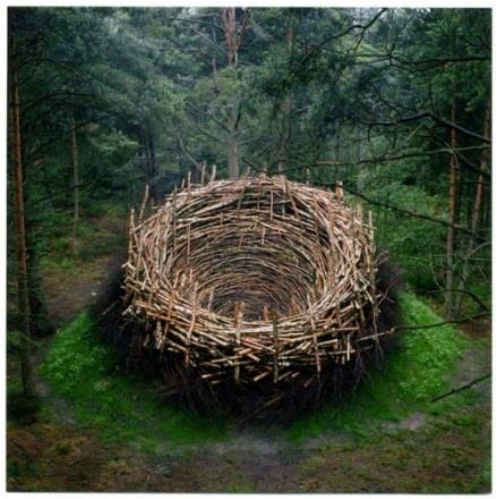

(شنكل-11)

الفصل الثالث اجراءات البحث مجتمع البحث تمثل مجتمع البحث في الاعمال الفنية المنجزة في عام 2020 في اورباو امريكا من خلال التحري و البحث للحصول على عينات البحث من الثبكة العنكبوتية العالمية. عينة البحث 
نم حصر 2 عينة بطريقة قصدية تثو افق مع اهداف البحث وما اسفر عنه الاطار النظري من مؤشرات وما يمتاز به الفنانيين من حضور فني متميز على صعيد القارة الاوربية و الو لايات المتحدة.

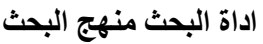

اعتمد الباحث على الملاحظة و المؤشرات التي اسفر عنها الاطار النظري في تتبع و الكثف عن ملامح الخطاب النحتي العالمي المعاصر.

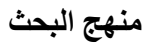
اعتمد المنهج الوصفي التحليلي على صعيد استخدام الخامة و طر ائق التشكيل و التقنية و اسلوب العرض.

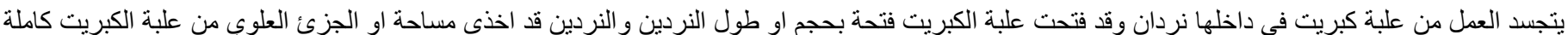

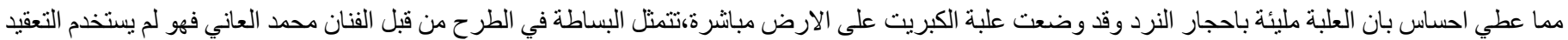

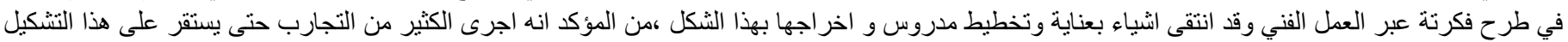

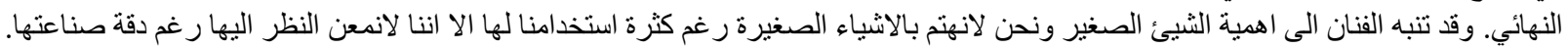

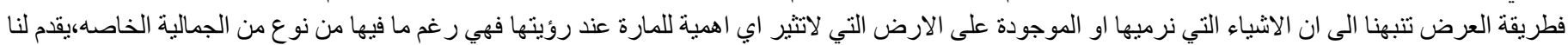

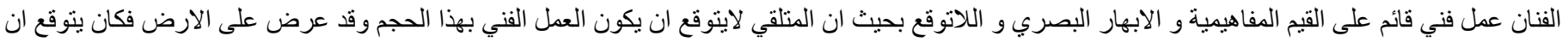

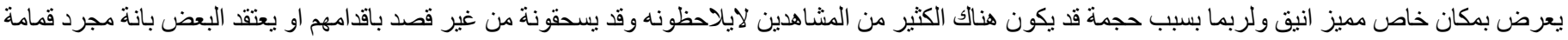

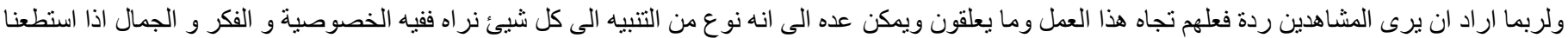

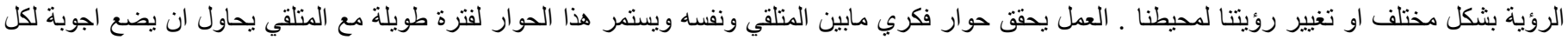
التساؤلات التي مرت بذ بذهنه

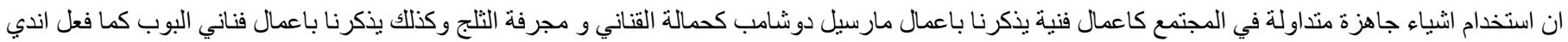

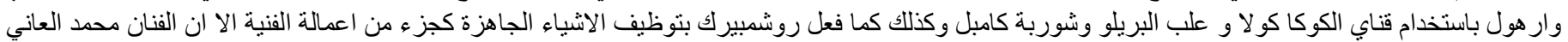

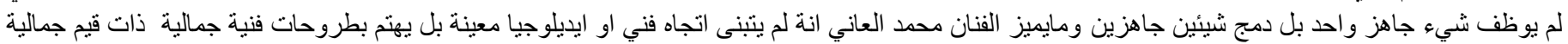

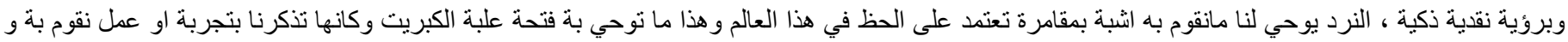

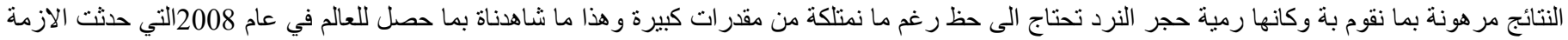

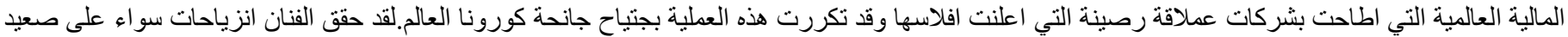

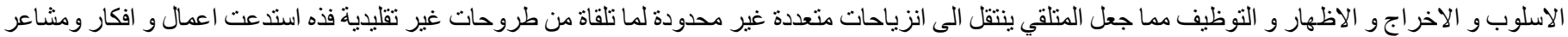

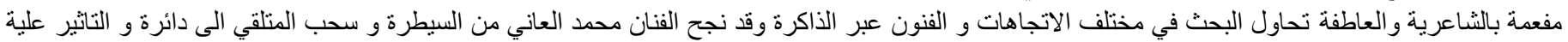


International Journal of Research in Social Sciences and Humanities

(IJRSSH) 2020, Vol. No. 10, Issue No. IV, Oct-Dec

http://www.ijrssh.com

e-ISSN: 2249-4642, p-ISSN: 2454-4671

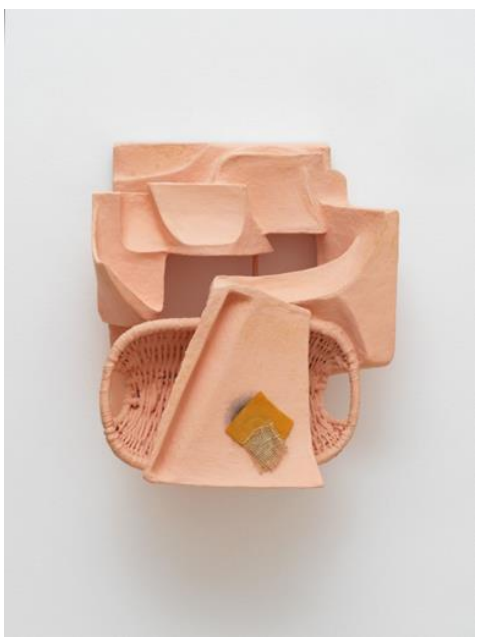

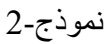

البلا: امريكا

الفنان: فنسنت فكتيو العنان

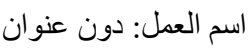

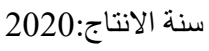

الخامة: ورق معجون ، سلة خوص ، أكريليك ، طين إيبوكسي ، لباد البكاد

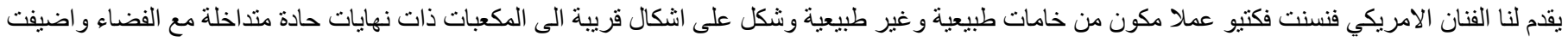

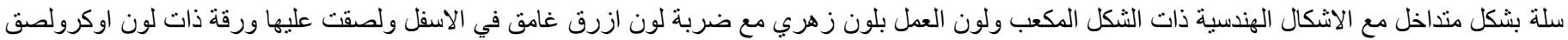

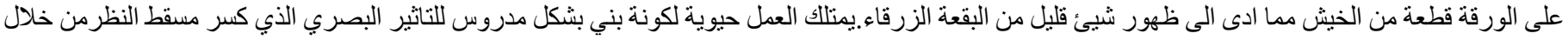

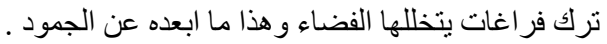

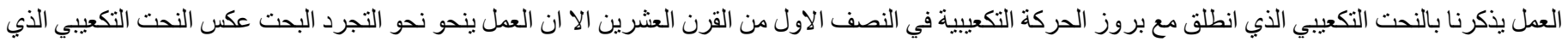

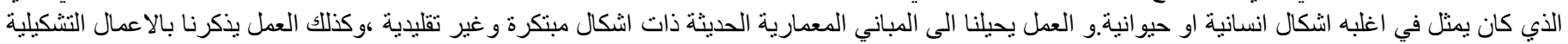

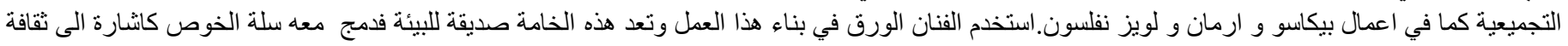

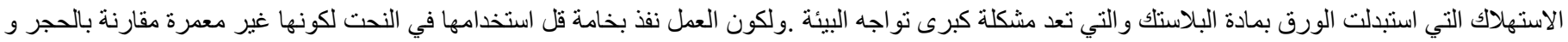

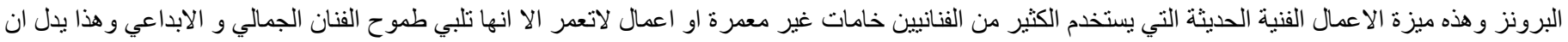

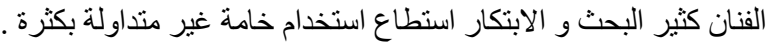

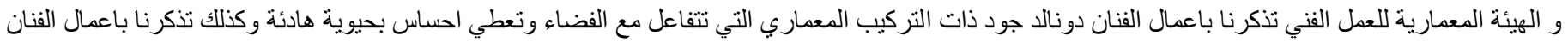

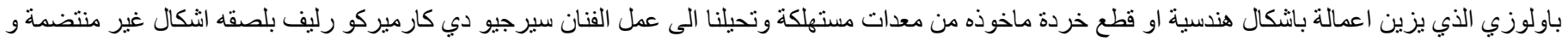

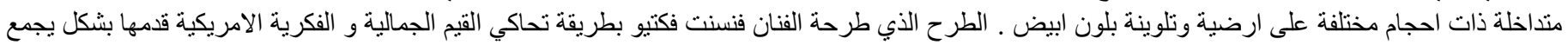

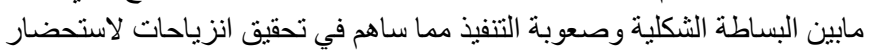

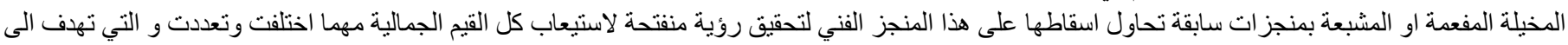
ابهار المتلقي . نتائج البحث:

1-اعتمدت الاعمال الفنية على الصور لاظهار الاعمال الفنية لخلق افكار ذهنية تقود الى الانزياح.

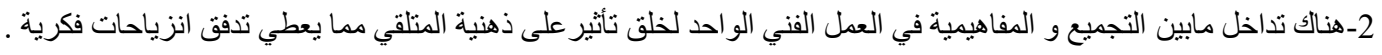

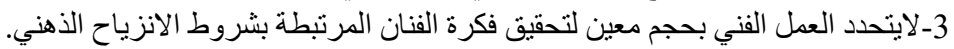

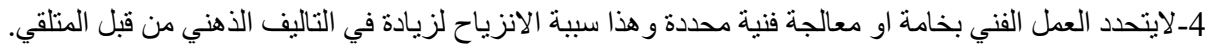

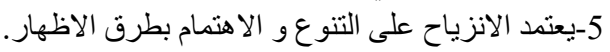

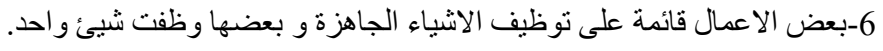

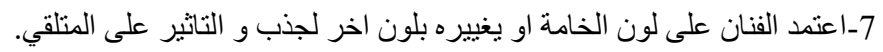

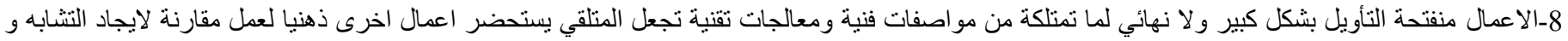




$$
\begin{aligned}
& \text { 10-لم يهتم الفنان بتشكيل اثكال انسانية وحيو انية لخلق انزياح ذهني مبانشر و انما اعتمد على التجريد لخلق انزياح مفاهيمي . } \\
& \text {-ابادي،م،ب(2005)|القاموس المحيط،بيروت،مؤسيسة الرسالة. }
\end{aligned}
$$

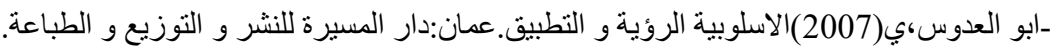

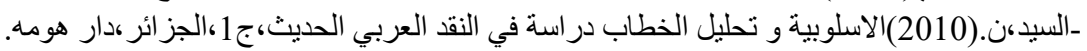

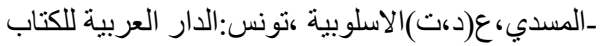

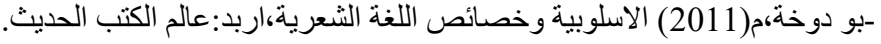

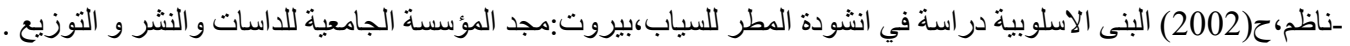

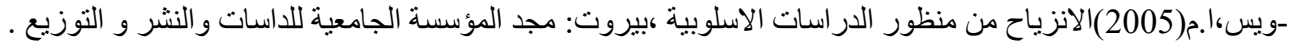

